\title{
Perfil das demandas judiciais cíveis por erro médico em Ginecologia e Obstetrícia no Estado de São Paulo
}

\section{Profile of civil litigation requirements for medical error claims in Gynecology and Obstetrics in the State of São Paulo}

\author{
Viviam Paula Lucianelli Spina ${ }^{1}$, Eduardo Costa Sá ${ }^{2}$
}

\begin{abstract}
Spina VPL; Sá EC. Perfil das demandas judiciais cíveis por erro médico em Ginecologia e Obstetrícia no Estado de São Paulo. Saúde, Ética \& Justiça. 2015;20(1):15-20.

RESUMO: Introdução: a sociedade se preocupa com a atuação do médico desde as civilizações mais antigas. O Código de Hamurabi (1790-1770 a.C.) foi o primeiro documento que fez referência à penalização da atuação médica frente ao dano provocado ao paciente. Atualmente, com a crescente judicialização da Medicina, nota-se um aumento das demandas judiciais indenizatórias por erro médico. Dentre as especialidades médicas com maior número de denúncias está a Ginecologia e Obstetrícia. Objetivo: identificar o perfil das demandas judiciais do Tribunal de Justiça do Estado de São Paulo por responsabilidade civil em casos julgados por erro médico em Ginecologia e Obstetrícia. Material e Métodos: Análise dos processos de primeira instância referenciados em 16 acórdãos do Tribunal de Justiça do Estado de São Paulo entre 01 de junho de 2013 e 31 de maio de 2014 e pesquisa nos bancos de dados Medline, Pubmed e Lilacs. Resultados: os autores foram sete $(44 \%)$ pacientes, oito $(50 \%)$ pacientes e cônjuge, os réus foram em nove vezes $(56 \%)$ os médicos, em treze $(81 \%)$ o hospital, em onze (69\%) na especialidade de Obstetrícia, em cinco (31\%) na Ginecologia, a prova pericial verificou nexo de causalidade em quatro (25\%) casos, considerou sem nexo de causalidade nove (56\%) casos. Conclusão: o perfil das demandas judiciais foi: os autores na sua maioria eram pacientes e cônjuges, na maior parte dos casos o Hospital foi o réu, a especialidade médica mais acionada foi a Obstetrícia, a prova pericial favoreceu o réu, os processos foram julgados improcedentes na maioria das vezes, as indenizações arbitradas nos casos de condenação do réu variaram entre de $\mathrm{R} \$ 40.000,00$ e $\mathrm{R} \$ 466.500,00$.
\end{abstract}

DESCRITORES: Erros Médicos; Reponsabilidade Civil; Ginecologia; Obstetrícia.

\footnotetext{
${ }^{1}$ Faculdade de Ciências Médicas da Santa Casa de São Paulo - FCMSCSP.

${ }^{2}$ Hospital das Clínicas da Faculdade de Medicina da USP; Instituto Nacional do Seguro Social; Faculdade de Ciências Médicas da Santa Casa de Misericórdia de São Paulo - FCMSCSP.

Endereço para correspondência: viviamspina@hotmail.com
} 


\section{INTRODUÇÃO}

sociedade se preocupa com a atuação
do médico desde as civilizações mais
antigas. O Código de Hamurabi (17901770 a.C.) foi o primeiro documento que fez referência à penalização da atuação médica frente ao dano experimentado pelo paciente. Pela aplicação da lei de Talião, os médicos eram sentenciados à amputação das suas mãos se houvesse a morte de um cidadão livre; se fosse um escravo, pagaria o seu preço. Os bárbaros na Europa, em particular os Visigodos e Ostrogodos, entregavam o médico à família do doente falecido por suposto erro médico, para que o justiçassem como bem entendessem ${ }^{1,2}$. Em Roma houve um importante desenvolvimento legislativo. No ano 451 a.C., destacase a Lei das XII Tábuas, que introduz a sanção penal frente aos casos de lesões pessoais. Na Lex Aquilia do século III a.C, encontram-se os primeiros rudimentos de responsabilidade médica, prevendo a pena de morte ou a deportação do médico culpado de falta profissional ${ }^{1}$.

$\mathrm{Na}$ Grécia, no século V a.C., constitui-se o Corpus Hippocraticum, o início das diretrizes de ética médica: "Aplicarei os regimes para o bem do doente segundo o meu poder entendimento, nunca para causar danos ou mal a alguém”, cuja síntese mais conhecida é o juramento médico, que ainda hoje é repetido por profissionais médicos em todo o mundo ${ }^{1}$.

O Código de ética médica do Conselho Federal de Medicina (CFM), no Capítulo I, item II, diz: "O alvo de toda a atenção do médico é a saúde do ser humano, em benefício do qual deverá agir com o máximo de zelo e o melhor de sua capacidade profissional" e no Capítulo III Art. I: "É vedado ao médico causar dano ao paciente, por ação ou omissão, caracterizável como imperícia, imprudência ou negligência. "3. Cabe ao CFM fiscalizar o respeito às normas do Código de ética médica e aplicar as sanções administrativas cabíveis.

Gomes e França definem o erro médico como o dano provocado ao paciente pela ação ou omissão do médico, no exercício da sua profissão, e sem a intenção de cometê-lo, podendo ser caracterizado por imperícia, imprudência e negligência ${ }^{2}$.

A imperícia corresponde à falta de observação das normas técnicas por despreparo prático ou insuficiência de conhecimento técnico; a imprudência caracterizase pela falta de cautela do médico, assumindo riscos desnecessários; e a negligência é a falta de observância aos deveres que as circunstâncias exigem, por omissão ${ }^{2}$.

Devemos diferenciar o erro médico do acidente imprevisível e do resultado incontrolável, visto que a atuação do médico é um compromisso de meios e não de resultados, ou seja, há casos em que, apesar de o médico ter empregado todos os recursos disponíveis, não obteve o sucesso pretendido. O acidente imprevisível é o mau resultado devido a caso fortuito ou de força maior, impossível de ser previsto ou evitado, independente da ação do médico; o resultado incontrolável é a evolução de curso inexorável, próprio do caso, para o qual a ciência médica não possui solução ${ }^{2}$.

A responsabilidade médica pode ser atribuída de duas maneiras: moral e legal. A responsabilidade moral, através de processo ético profissional nos Conselhos de Medicina, e a responsabilidade legal, por ação Civil ou Penal nos tribunais de justiça.

Do ponto de vista moral e ético, o erro médico é imputado pela aplicação do Art. I do Capítulo III do Código de Ética Médica².

No Código Civil há vários artigos que descrevem o dano a outrem e suas repercussões de responsabilidade, em que o erro médico pode ser incluído na sua interpretação. No Art. 186. "Aquele que, por ação ou omissão voluntária, negligência ou imprudência, violar direito e causar dano a outrem, ainda que exclusivamente moral, comete ato ilícito"; No Art. 927. "Aquele que, por ato ilícito (arts. 186 e 187) causar dano a outrem, fica obrigado a repará-la. ${ }^{5,6}$.

França descreve que devem estar presentes os seguintes elementos para a caracterização de responsabilidade civil do erro médico: o médico deve estar legalmente habilitado, deve haver um ato lícito, a presença da culpa, presença de dano real e nexo causal entre ato e dano ${ }^{4}$.

Devemos diferenciamos culpa e dolo, na semântica do Direito. Culpa é a conduta voluntária, porém descuidada de um agente, que causa um dano involuntário, previsível ou previsto, a outrem. Dolo é a conduta voluntária e intencional de alguém que, praticando ou deixando de praticar uma ação, com o objetivo de um resultado ilícito ou causar dano a outrem.

Há vários anos o Poder Judiciário Brasileiro vem sendo assolado por um fenômeno conhecido como a "indústria do dano", ou seja, a busca incessante e muitas vezes desnecessária de prestação jurisdicional por indivíduos que alegam danos hipotéticos com pedido de indenizações infundadas e inconsequentes, em busca de ganho patrimonial indevido?

Atualmente, com a Judicialização da Medicina, são cada vez mais comuns as demandas indenizatórias, através das quais os pacientes pleiteiam uma compensação patrimonial em virtude de supostos danos experimentados em alegado erro médico ${ }^{8}$.

O Superior Tribunal de Justiça, nos últimos dez anos, refere que o país teve um aumento de $1.600 \%$ 
no número de processos judiciais envolvendo médicos tanto na esfera Civil como na Penal ${ }^{7}$.

Dentre as especialidades médicas de maior número de denúncias por erro médico está a Ginecologia e Obstetrícia. O Conselho Regional de Medicina de São Paulo informa que entre os anos de 1996 e 2002 houve 12 mil denúncias ético profissionais, sendo esta a principal especialidade, com $12 \%$ das denúncias, em que $86 \%$ referiam-se à especialidade Obstetrícia e 14\% à Ginecologia ${ }^{9}$.

Como a Ginecologia e Obstetrícia são as especialidades médicas com maior número de denúncias judiciais por erro médico na esfera da Justiça Civil, é assunto de grande interesse tanto da Medicina como da Justiça.

\section{OBJETIVO}

Dada a importância do estudo do erro médico na especialidade de Ginecologia e Obstetrícia, o objetivo deste estudo é identificar o perfil das demandas judiciais do Tribunal de Justiça do Estado de São Paulo por responsabilidade civil em casos julgados por erro médico em Ginecologia e Obstetrícia em um período de 2013 a 2014.

\section{MATERIAL E MÉTODOS}

Foram analisados os dados dos processos de primeira instância descritos em 22 acórdãos do Tribunal de Justiça do Estado de São Paulo. Tais registros foram verificados pelo site http://www.tjsp.jus.br/, na área do Advogado, consulta de Jurisprudência, usando os descritores erro médico, Ginecologia e Obstetrícia, origem: $2^{\circ}$ grau, tipo de decisão: acórdãos, data de registro entre 01 de Junho de 2013 e 31 de Maio de 2014.

Realizada pesquisa no banco de dados: Medline, Pubmed e Lilacs, envolvendo os anos compreendidos entre 2000 e 2013. Os descritores utilizados foram: erro médico, Ginecologia Pre Obstetrícia e responsabilidade civil.

Os critérios de exclusão foram os seguintes: um acórdão em que a demanda foi motivada por erro no resultado de exame laboratorial, dois acórdãos em que o procedimento médico realizado foi estético, um relativo à afiliação de médico em cooperativa de trabalho, um referente à tributação de ISS em clínica médica e um por duplicidade de acórdãos. Restaram então 16 acórdãos para o estudo.

\section{RESULTADOS}

Os autores que moveram a ação foram sete (44\%) pacientes, oito $(50 \%)$ pacientes e respectivos cônjuges à época da ação, e um (6\%) cônjuge e filhos.

Os réus apresentaram diversas formas de associação, sendo nove vezes (56\%) os médicos assistentes, treze vezes ( $81 \%$ ) o hospital e cinco vezes (31\%) o convênio médico.

As motivações por erro médico foram as seguintes:

A. Atraso na realização do parto, descolamento prematuro de placenta com feto natimorto.

B. Diagnóstico tardio de câncer de mama, paciente sofreu extirpação desnecessária de uma mama.

C. Deficiência no atendimento prestado a gestante ocasionando óbito fetal.

D. Laudo de mamografia errado (Birads 3 doença benigna), com diagnóstico de câncer de mama após cinco meses.

E. Gestante de 39 semanas procurou PS, sendo dispensada por falso trabalho de parto, morte de feto subsequente.

F. Aplicação de fórceps no parto ocasionado traumatismo crânio encefálico e morte do nascituro.

G. Lesão de colón sigmoide em procedimento de histerectomia.

H. Realização de laqueadura não autorizada.

I. Gestação de risco (pré-eclâmpsia), ausência de médico no atendimento a gestante, sem transferência da paciente, feto natimorto.

J. Falha de atendimento prestado pelo hospital, assistência ao parto (cesáreo) em gestante de 39 semanas, recém-nascido evoluiu com bronco aspiração e choque séptico, óbito do neonato algumas horas após o nascimento.

K. Gestante de 42 semanas, atendimento de PS, gestante dispensada por falso trabalho de parto, óbito fetal intrauterino após dois dias.

L. Cirurgia para correção incontinência urinaria (técnica de Burch) e colpoperineoplastia posterior realizadas desnecessariamente devido à doença de grau leve, cursou com grave complicação, dobra de ureter, necessitando de novo procedimento cirúrgico, além de realização de ninfoplastia com resultado não satisfatório.

M. Atendimento deficiente a gestante no PS, óbito fetal intrauterino subsequente (malformação cardíaca fetal).

N. Falha no atendimento a gestante com gestação gemelar de 37 semanas, atendida no PS, dispensada por falso trabalho de parto, com óbito de um dos fetos dois dias após o primeiro atendimento.

O. Sequência de diagnósticos desencontrados envolvendo a gravidez da autora (prenhez ectópica), 
que levou à perda desnecessária de uma trompa.

P. Falha no atendimento da parturiente e da recém-nascida, subsequente óbito da genitora e sequelas à recém-nascida.

Em relação à especialidade médica, onze (69\%) casos das demandas foram na especialidade de Obstetrícia e cinco (31\%) casos de Ginecologia.

A prova pericial verificou nexo de causalidade, ou seja, favorável ao autor em quatro (25\%) casos, sem nexo de causalidade, favorável ao réu em nove $(56 \%)$ casos, em um $(6 \%)$ processo não houve menção da prova pericial médica, em um $(6 \%)$ caso não foi realizada perícia e em um $(6 \%)$ caso foi relatada como incompleta.

Os processos foram julgados improcedentes em dez $(63 \%)$ casos, procedentes em cinco $(31 \%)$ e um $(6 \%)$ caso foi prescrito.

Nos casos em que houve condenação do réu, os valores arbitrados pelo juízo foram de $\mathrm{R} \$ 40.000,00$, $\mathrm{R} \$ 60.000,00, \mathrm{R} \$ 169.500,00, \mathrm{R} \$ 340.000,00$ e $\mathrm{R} \$$ $466.500,00$.

\section{DISCUSSÃO}

No estudo, as motivações das queixas na especialidade de Ginecologia foram diversas. As queixas referentes a resultado adverso foram devidas a eventos que podem ocorrer e que são estatisticamente descritos na literatura médica em tais procedimentos.

Nogueira-Silva et al descrevem a ocorrência de complicações do procedimento cirúrgico ginecológico de histerectomia, podendo ocorrer lesão ureteral, lesão vesical, perfuração intestinal, hemorragia, complicações anestésicas, embolia pulmonar; lesão da serosa intestinal, infecção, trombose venosa profunda e incontinência urinária; eles analisaram 549 histerectomias e verificaram a lesão de serosa intestinal em dois $(0,76 \%)$ casos $^{10}$.

Nas demandas judiciais em Ginecologia do presente estudo, a maior parte dos casos foi de intercorrências e complicações inerentes ao procedimento cirúrgico ginecológico.

Já na especialidade de Obstetrícia, em 10 dos 11 casos a motivação foi devida ao atendimento prestado à gestante no pronto socorro ou na assistência ao parto, evoluindo com o óbito fetal posterior.

A Obstetrícia, dentre as especialidades médicas, é uma das mais visadas no que se refere à responsabilidade civil no âmbito jurídico, pois não trata de um paciente comum em curso de uma doença que necessita de tratamento e recuperação e, sim, trata-se de uma mulher, na maioria das vezes saudável, em curso de um processo fisiológico, a gestação, que evolui sem intercorrências na sua grande parte, ocorrendo, contudo uma parcela de gestações em que há complicações que podem evoluir para um de desfecho materno-fetal desfavorável.

Existem inúmeros fatores de risco para a ocorrência de complicações na gestação e no parto, como os biológicos: idade menor que 16 anos ou maior que 35 anos, peso inferior a $50 \mathrm{Kg}$, estatura inferior a 1,50 $\mathrm{m}$ e história familiar de doenças hereditárias; os clínicos e ambientais: hipertensão, nefropatia, diabetes, cardiopatia e doença sexualmente transmissível; os comportamentais: fumo, etilismo, uso de drogas, trabalho braçal e sedentarismo; aqueles relacionados à assistência médica: má qualidade de assistência, cobertura insuficiente da rede e falta de integração interinstitucional; os obstétricos: história de infertilidade, gravidez ectópica, aborto espontâneo, anomalias uterinas, feto macrossômico, antecedente de natimorto, recém-nascido de baixo peso, multiparidade, mola hidatiforme, coriocarcinoma e cicatriz uterina prévia e os relacionados às condições atuais: pré-natal ausente ou tardio, hemorragias, gestação múltipla, ruptura prematura de membranas, hipertensão induzida pela gestação, aloimunização, gestação prolongada, retardo de crescimento intrauterino, polidrâmnio, anemia e apresentação anômala ${ }^{11}$.

As expectativas da gestante, do cônjuge e dos familiares costumam ser as mais prósperas possíveis: alegria, entusiasmo, satisfação, comemorando a chegada de um novo ente da família. Caso ocorra algum evento adverso com prejuízo materno ou fetal, as expectativas são substituídas abruptamente por frustração, dor e descontentamento. O inconformismo gerado promove a delegação de culpa à assistência médica e hospitalar, sendo denominada como "erro médico", independente da presença ou não de nexo de causalidade entre o dano sofrido e a atuação médica.

No âmbito jurídico, a obrigação do médico é de meios e não de resultado, o que significa que o médico deve fazer uso da técnica e dos recursos disponíveis, agir com prudência e diligência, empregando todos os meios para obter o sucesso na assistência ao paciente, não estando, no entanto, obrigado a alcançá-lo.

Ressalta-se que não é rotina dos médicos obstetras discutir com suas pacientes e familiares, todos os fatores de risco, as complicações e eventuais resultados adversos para o binômio materno fetal no pré-natal e trabalho de parto.

Do ponto de vista epidemiológico, como descreve a literatura médica, há percentuais esperados na população geral de complicações na gravidez e parto, com diversos fatores causais, fatores de risco e sendo 
descritos ainda óbitos fetais de causa desconhecida.

Magalhães et al. analisaram 2058 adolescentes grávidas e os riscos obstétricos, e constataram que $88 \%$ frequentaram o pré-natal, sendo $60 \%$ com número insuficiente de consultas. As intercorrências clínicas mais frequentes foram a pré-eclâmpsia $(14,7 \%)$, a anemia $(12,9 \%)$ e a infecção do trato urinário $(6,4 \%)$. Malformações congênitas foram diagnosticadas em 56 $(2,7 \%)$ e houve $58(2,8 \%)$ de óbitos neonatais ${ }^{12}$.

De Aquino e Cecatti realizaram um estudo numa instituição de atendimento obstétrico na cidade de São Paulo, entre os anos de 1996 e 1997 em que foram analisados 122 casos de gestantes com diagnóstico de óbito fetal e suas causas. A causa mais prevalente foi a hipertensão arterial em $30 \%$ dos casos, causas infecciosas em $13,2 \%$, e em $24,6 \%$ dos casos não se pode definir a causa do óbito fetal ${ }^{13}$.

A perícia médica definida por França como "um conjunto de procedimentos médicos e técnicos que tem como finalidade o esclarecimento de um fato de interesse da Justiça" atua como meio de prova no processo, procedimento pelo qual se verifica a veracidade ou não de fatos alegados em juízo. O exame pericial deve ser pautado nas normas técnicas, científicas e jurídicas, para que bem sirva o seu objetivo de auxiliar a Justiça e esclarecer fatos obscuros para o julgador $(4,14)$.

No presente estudo, a prova pericial verificou nexo de causalidade com a queixa do autor em 4 (25\%) dos casos e ausência de nexo de causalidade em 9 (56\%) dos casos.

Verificamos que mais da metade das ações (63\%) foram julgadas em improcedentes. $\mathrm{Na}$ especialidade de Ginecologia, dos cinco casos, quatro (80\%) foram improcedentes, e na especialidade de Obstetrícia, dos 11 casos, seis (55\%) foram julgados improcedentes. Nota-se que na maioria das ações deste estudo não houve caracterização de erro médico pelo juízo.

Segundo Coltri, aproximadamente $75 \%$ das demandas judiciais por erro médico são julgadas improcedentes, ou seja, a cada 4 médicos, 3 deles são processados injustamente ${ }^{15}$.

Neste estudo, o valor arbitrado nos casos em que réu foi condenado variou de $\mathrm{R} \$ 40.000,00$ a $\mathrm{R} \$$ $466.500,00$, indicando altos valores de indenização nos casos julgados procedentes.

A Medicina, devido à sua área de atividade, conta com diversos fatores adversos que podem causar danos ao paciente. Contudo, estes danos nem sempre podem ser considerados "erros médicos". A profissão do médico é de alto risco, e o êxito de seu trabalho não depende exclusivamente de seu ato, mas também de múltiplos fatores que independem de sua vontade. Porém o paciente, ao se deparar com o evento adverso, favorecido pelo próprio sistema Jurídico, com o auxílio da justiça gratuita, pode vir a se aventurar judicialmente em busca de benefício financeiro?

Vários fatores estão envolvidos no aumento do número de processos por erro médico, dentre eles, a deterioração da relação médico-paciente, a maior conscientização da população acerca de seus direitos, o fortalecimento dos direitos do consumidor, a precarização das condições de trabalho, principalmente no setor público, a democratização do acesso ao Poder Judiciário, o nível de informação alcançado pelos pacientes e, consequentemente, o aumento da sua exigência quanto ao serviço médico e a influência da mídia ${ }^{2,7}$.

Dentre estes fatores, destaca-se a deterioração da relação médico-paciente. O médico antigamente estava esmerado aos costumes e havia uma estreita ligação com seus pacientes, compartilhando uma relação de respeito, confiança, estima e às vezes até de amizade. Porém, ao longo dos anos as modificações do sistema de saúde levaram à institucionalização dos pacientes, com o distanciamento entre o médico e seu paciente, o médico atuando com medo através de uma Medicina defensiva que culmina com uma relação impessoal e de desconfiança recíproca ${ }^{2}$.

A boa relação médico-paciente é a melhor maneira de prevenir os processos contra médicos, sendo esta marcada pelo respeito, afeição, transparência e autonomia. Além da devida e completa informação, ao paciente e seus familiares, dos fatores de risco, das complicações, dos eventos imprevisíveis, e dos desfechos desfavoráveis que podem vir a ocorrer no pré-natal e trabalho de parto, a fim de atingir alto grau de compreensão, tolerância e confiança entre o médico e seu paciente ${ }^{2}$.

\section{CONCLUSÃO}

Após analisar os dados dos processos de primeira instância contidos nos acórdãos do Tribunal de justiça do Estado de São Paulo referentes ao período 01 de Junho de 2013 a 31 de Maio de 2014, identificamos como perfil das demandas judiciais deste tribunal por responsabilidade civil nos casos julgados por erro médico em Ginecologia e Obstetrícia que os autores, na sua maioria, eram pacientes e cônjuges, o réu que mais prevaleceu foi o Hospital, a especialidade médica mais acionada foi a Obstetrícia, a prova pericial foi favorável ao réu na maior parte dos casos, pois a maioria dos processos foram julgados em improcedentes, e, nos casos procedentes, as indenizações proferidas foram de valores entre $\mathrm{R} \$ 40.000,00$ e $\mathrm{R} \$ 466.500,00$. 
Spina VPL; Sá EC. Profile of civil litigation requirements for medical error claims in Gynecology and Obstetrics in the State of São Paulo. Saúde, Ética \& Justiça. 2015;20(1):15-20.

\begin{abstract}
Introduction: society concern about doctors' performance goes far back in history to the most ancient civilizations; the Code of Hammurabi (1790-1770 BC) was the first document that made reference to criminalization of medical action for damage caused to a patient. Currently, with the increasing legal aspects of Medicine, there has been an increase in indemnity demands as a consequence of judicial malpractice. Gynecology and Obstetrics are among the medical specialties with the highest number of complaints. Objective: To identify the profile of litigation of the State Court of São Paulo for civil liability in cases judged as medical errors in Obstetrics and Gynecology. Methods: the first instance processes referenced were analyzed in 16 judgments of the São Paulo State Court of Justice between June 1, 2013 and May 31, 2014, and research was carried out on the databases Medline, Pubmed and Lilacs. Results: The plaintiffs were seven $(44 \%)$ patients, eight $(50 \%)$ patients and spouse, the defendants were nine $(56 \%)$ doctors, thirteen $(81 \%)$ hospitals, eleven $(69 \%)$ cases in Obstetrics, in five (31\%) in Gynecology, the expert evidence found causation in four (25\%) cases, no causal link in nine $(56 \%)$ cases. Conclusion: the profile of litigation showed that the plaintiffs were mostly patients and spouses, the defendants were mostly hospitals, the medical specialty most involved was the Obstetrics, the expert evidence favored the defendant, the cases were dismissed most of the time, damages arbitrated in cases of conviction of the defendant vary between $\mathrm{R} \$ 40,000.00$ and $\mathrm{R} \$ 466,500.00$.
\end{abstract}

KEY WORDS: Medical Errors; Damage Liability; Gynecology; Obstetrics.

\section{REFERÊNCIAS}

1. Dantas EVS. Aspectos históricos da responsabilidade civil médica. [Internet]. JUS Navigandi: R7; 2003 [acesso em 2015 abr 06]. Disponível em: http://jus.com.br/artigos/4288/ aspectos-historicos-da-responsabilidade-civil-medica/2

2. Gomes JCM, Drummond JGF, França GV. Erro médico. $3^{\mathrm{a}}$ ed. Montes Claros: Unimontes; 2001.

3. Brasil. Conselho Federal de Medicina. Resolução CFM No 1931/2009, de 24 de setembro de 2009. Aprova o Código de Ética Médica. Diário Oficial da União. 2009 set 24; Seção 1. p. 90. e Retificação publicada no D.O.U. de 13 de outubro de 2009, Seção I, p.173.

4. França GV. Medicina legal. $7^{\mathrm{a}}$ ed. Rio de Janeiro: Guanabara Koogan; 2004

5. Brasil. Presidência da República. Casa Civil. Subchefia para Assuntos Jurídicos. Lei n. 10.406, de 10 de dezembro de 2002. Institui o Código Civil. [Internet]. Diário Oficial da União. 2002 jan 11 [acesso em 2014 nov 16]. Disponível em: http://www.planalto.gov.br/civil_03/leis/2002/:110406. htm

6. Dimas Júnior BT. Responsabilidade civil do médico. Revista Jurídica do Uniaraxá. 2000; 4(4):181-94.

7. Bernardes $\mathrm{A} . \mathrm{O}$ médico e a indústria do dano. [Internet]. JUS Navigandi: R7; 2015 [acesso em 2015 jan 08]. Disponível em: http://jus.com.br/artigos/36673/o-medicoe-a-industria-do-dano

8. Canal R. Erro Médico e Judicialização da Medicina. Brasília: Saturno; 2014. 288p

9. CREMESP - Conselho Regional de Medicina do Estado de São Paulo. Manual de ética em Ginecologia e Obstetrícia.
[Internet]. 1999 [acesso em 2015 jan 05]. Disponível em: http://www.cremesp.org.br/?siteAcao=Publicacoes\&acao $=$ detalhes_capitulos\&cod_capitulo $=52$

10. Nogueira-Silva C, Santos-Ribeiro S, Barata S, Alho C, Osório F, Calhaz-Jorge C. Histerectomia Totalmente Laparoscópica: Análise Retrospectiva de 262 Casos. Acta Med Port. 2014; 27(1):73-81.

11. Freitas F, Martins-Costa SH, Ramos JGL, Magalhães JA et.al. Rotinas em Obstetrícia. $6^{\mathrm{a}}$ ed. Porto Alegre: Artmed; 2011.

12. Magalhães MLC, Furtado FM, Nogueira MB, Carvalho FHC, Almeida FML, Mattar R, et.al. Gestação na adolescência precoce e tardia - há diferença nos riscos obstétricos? Rev Bras Ginecol Obstet. 2006; 28(8):446-52. DOI: http://dx.doi.org/10.1590/S010072032006000800002

13. De Aquino MMA, Cecatti JG. Epidemiologia do óbito fetal em população de baixa renda. Rev Bras Ginecol Obstet. 1998; 20(2):71-5. DOI: http://dx.doi.org/10.1590/ S0100-72031998000200003

14. Coelho BF. A importância da perícia médico-legal para o processo penal na persecução da verdade real. [Internet]. Âmbito Jurídico; 1999 [acesso em 2015 abr 06]. Disponível em: http://www.ambito-juridico.com.br/site/index.php?n link=revista_artigos_leitura\&artigo_id $=9789$

15. Coltri MV. O médico e o custo para provar sua inocência. [Internet]. São Paulo; 2011 [acesso em 2015 abr 06]. Disponível em: http://www.ducatri.com.br/diferencial/ rcp.pdf 